\title{
Edward Shorter \\ Partnership For Excellence: Medicine at the University of Toronto and Academic Hospitals
}

\author{
Toronto: University of Toronto Press, 2013. 903 pp.
}

\section{Erika Dyck}

University of Saskatchewan

Shorter this book is not. Edward Shorter has written over twenty books on topics within the history of medicine, and this one may well be the longest yet. It explores the history of medical education at the University of Toronto over the course of the twentieth century as the university moved from a provincial school catering to rural Ontario farm boys to an "international powerhouse" (inside cover) attracting students and faculty from all over the world. By the end of its 750 pages of text, divided into 30 chapters, readers are left with a dizzying array of details supporting Shorter's overall contention that the University of Toronto, with its medical school and its affiliated hospitals, is an internationally recognized leader in teaching and research, and among the top North American schools of medicine. Moreover, its success is both because and in spite of the collected assortment of hospitals, departments, and personalities that have all been harnessed together under strong leadership. Writing this history is no easy task, but Shorter has done it with characteristic flare for colourful anecdotes and a writing style that breathes humour and wit into an otherwise daunting array of administrative memos, program reviews, and strategic planning documents.

The title is an appropriate moniker for what is in essence a study of partnerships. The main partnership concerns the university and the hospitals - nine in total, including Toronto Sick Children's Hospital, Toronto General Hospital, Sunnybrook Health Sciences Centre, Princess Margaret's Hospital, St Michael's Hospital, and the Centre(s) for Addiction and Mental Health. Nowhere else in Canada is there such a rich geographical concentration, even as one travels north as far as the Sunnybrook campus, stretching the collaboration beyond reasonable walking distance. Proximity is an important feature of this partnership, but as Shorter demonstrates, it has been 
historically significant for developing a rather fluid relationship for teaching, research, and clinical work.

The partnership between teaching and research is another central theme. Shorter describes that transformation of the University of Toronto medical complex as one that moved from primarily teaching medical students to one that has become a world leader in research. This evolution, he suggests, is not by accident, but is the direct result of decanal visions for an internationally significant research agenda, from which good teaching naturally followed. The historical context helps to show how such innovation occurred, and the resultant shift in student demographics, from farm boys to war veterans to increasing numbers of women and Jews, and ultimately to a cosmopolitan and global mixture of students that better reflects the multicultural nature of Toronto itself. Shorter contends that research was the main driver that kept the University of Toronto ahead of its competitors.

Another salient partnership involves funding. Shorter points to the many private benefactors who came up with funding to secure professorships, maintain a research idea, or establish more space — all three items have been identified as critical to designing a successful model.

International partnerships shifted, from Britain to Canada in the first half of the century, and then from the United States to Canada, and later still from a wider set of international resources. Although Shorter does not identify it as such, there is also a more stable relationship between Toronto and the rest of Canada, with the University of Toronto drawing motivated students, researchers, and leaders from all parts of the country. The flow of traffic seems to favour people moving into the nexus of the medical world in Toronto, while ideas, technologies, patents, and treatments moved outward from this site of innovation.

One of the final, and perhaps most significant, partnerships, for this reviewer, are the myriad relationships that form, grow, break apart, and reform under the umbrella of disciplines or departments or research institutes. Although tracking these changes is tedious and challenging to follow as Shorter moves back and forth in time with each new organizational thread. The sum of these stories provides detailed insight into the evolution of clinical medicine and its professionalization. Within this subtheme, the influence of technology is impossible to ignore. In fact, Shorter's interpretation suggests that changes are often led by technological innovation, around which a discipline forms, after which it breaks off into its own departmental structure as it demands its own space, funding, curriculum, etc.. But, as Shorter points out, this sub-specialization has some limits. As medical schools used to essentially fold all the bio-medical sciences under physiology before specialization splintered the curriculum into numerous capillaries of bodily systems and their affiliated tools and techniques, the pendulum is in some ways swinging back towards medical education that favours broad-based learning, with room for continuing education throughout one's clinical career. Physiology, it seems, may re-inherit this foundational role as the main artery running through the heart of a medical education.

One is hard pressed to find Shorter criticizing the University of Toronto's path to medical excellence. His heavy reliance on administrative documents and external 
program reviews furnishes him with plenty of public-relations-approved language to promote an insider's view of this institutional complex in a manner that praises a long history of administrative vision alongside a nimble structure that was flexible enough to take advantage of serendipity. The deep concentration of facilities presents a formidable administrative and structural challenge, but as Shorter plainly states: "the faculty has had a series of unusually gifted leaders to help yoke the locomotives together" (4). The book examines those leaders in great detail, exploring their influences on the success of the complex while often overlooking other contextual factors, whether those be patients, families (of patients or students), macro-economics of health care in Canada, health policy, even Medicare, or developments in other medical institutions throughout Canada or elsewhere. While Shorter states that, "this is not hagiography" (6), readers with less admiration for university administrators may find this account a rather tough pill to swallow. 